\title{
The architecture of energy systems between technological innovation and environment
}

\author{
Laura Daglio ${ }^{*}$ (1) and Elisabetta Ginelli
}

\begin{abstract}
This paper has the aim of defining possible interpretive models concerning the integration of energy infrastructures and landscape, highlighting emerging issues and drafting future paths for further development through technological innovation of energy systems and beyond. A taxonomy of different design approaches is disclosed, portraying different energy landscapes and supported by a selection of case studies (built and concepts) in a historical perspective. Whilst the research towards alternative sources of energy has recently downsized, albeit considered determining at the beginning of the century, technological change moves towards the enhancement of the existing common sources, an incremental innovation which benefits from well-established experiences and therefore affordable in terms of availability and size of investments. Product innovation trends are directed towards an increased upgrading and advancement in order to develop flexibility in architectural integration or to improve energy storage systems for a widespread uptake of microgeneration. Finally, the paper emphasizes the need for an active, bottom-up involvement of society in the energy transition and thus in landscape transformation, a perspective requiring a rethinking of energy laws and market regulations still strongly related to top-down energy policies and oligopoly.
\end{abstract}

Keywords: Energyscapes, Technological innovation, Participation

\section{Energy as a driving force behind landscape transformation}

Energy has been one of the main driving forces behind landscape transformation since ancient times (Pasqualetti 2012). However, in the current period of transition we're beginning to notice that renewable energies have triggered a qualitative leap in landscape's physical alteration and representation. Such an improvement is about to determine substantial changes, which are going to extend over the 21 st century-an outcome equalled only by the exploitation of fossil fuels started during the Industrial Revolution. In a temporal perspective, given data about the current clear majority of traditional sources (International Energy Agency 2015b), the spreading of renewable energies is undoubtedly bound to increase. Among the most effective agents of these modifications on a global

\footnotetext{
*Correspondence: laura.daglio@polimi.it

Dep. of Architecture, Built Environment and Construction Engineering, Politecnico di Milano, Via Ponzio, 31, 20133 Milan, Italy
}

scale we can obviously list also climate change, population growth and the development of world's economies with relative side effects. But the specific nature of low carbon energy systems-isolated and confined as in the case of traditional production on one hand, pervasive and widespread on the other-makes them a subsystem, a distinct layer in landscape's spatial structure and notion (Stremke 2014). This presence becomes even more decisive if we consider these systems on the basis of their complex life cycle, of the material and immaterial relations they establish or as partial expression of a more general shift towards carbon neutrality: this would imply emission reduction in energy production and all industrial sectors, but also a set of measures to counterbalance emissions such as vegetable biomass enhancements.

And yet, the pervasiveness of energy systems, or better still plant systems-unquestionably late from a cultural point of view-raises contrasts and debates, being an added and superstructural element which rarely integrates successfully. 


\section{Energy in contemporary landscape: interpretative models}

Integration into landscape has been carried out with ever-increasing prevalence on the basis of the objectives established and developed over time by international environmental conferences-as well as adopted and applied by European and national policies. Moreover, this process developed in accordance with ways and behaviours which can differ considerably from one another and still be classified into various macro-categories.

Such disparity comes from a specific vision of the pair innovation/nature (still essentially antithetic) and the preponderance of an aesthetic-perceptive landscape concept. Two cultural approaches prevail, carrying on an idea of technological innovation which is both romantic and adherent to Enlightenment principles; thus, they emphasize the underlying paradox of conservation against sustainability, which likewise aim at the transmission of values and resources to the next generations.

The first approach is static-conservative. It distinguishes the landscapes which can be preserved from the degraded-thus eligible to freer transformations-ones, as well as the "acceptable" technologies generally mitigating or integrating with ease. This perspective imbues most of the land planning and regulation tools, at least in Italy, and helps identifying environmental protection areas precluded from possible transformations. In this sense the law-maker seems to interpret a common, shared nostalgic representation of landscape as a historical or supposedly natural domain which is to be preserved, and consequently sometimes independent from any perceived quality.

Restriction landscape raises several issues: in terms of policies, e.g. to what degree and how territory government tools accept the idea of cultural landscape; or from a disciplinary point of view, such as analysis, interpretation and settlement methods of a potential intervention on the land. Moreover, given the historical density and geographic variety of Italian territory where it could be enforced, it seems like it won't make room (literally) for the integration of renewable energies and those transformations aimed at achieving neither environmental, nor economic or social sustainability objectives. On one hand, the denial of transformation or transformability risks condemning the land to develop a "museum-like" aspect, immediately evoking the ageold opposition between valorisation and preservation; ${ }^{1}$ on the other, further possible interpretations generated

\footnotetext{
${ }^{1}$ In this sense, for instance, tourism industry as an activity potentially damaged by energy infrastructure integration is opposed to the potential economic development such infrastructures could produce wherever they're hosted.
}

by the static-conservative approach leave some doubts about efficiency in terms of temporal continuity, and produce a landscape representing a culturally controversial and contradictory society from the legislation systems' perspective. Mitigation landscape, in particular, forms several design choices or the good practice of some regulation tools, manifesting itself in the guise of both visual concealment-an unhistorical but efficient compromise between aesthetics and performance ${ }^{2}$-and mimesis, whose results are disparate but often very close to a camouflage of forms and materials sometimes verging on grotesque. ${ }^{3}$ Unfortunately, the technological innovation developed by component producers moves even in this kind of market, offering hybrid and poorly integrated solutions-technological fakes such as solar tiles, imitation slate slabs or solar panels disguised as roof windows, where the relation shape/function is disrupted to the benefit of kitsch. At the same time, the technological pastiche responds both to a deviation of taste and the heterogeneity between local regulation (building codes, colour plans, etc.) and regional or national laws (legislation on energy efficiency) or among different but often neighbouring territorial scopes. In this respect, regulations on the installation of solar panels in areas subject to landscape and environmental restriction (from the historic centre to the restricted buffer zones near drainage basins) are a perfect example. First they've been forbidden, then submitted to the superintendent's opinion-with all the resulting consequences-and finally used when applying to a regional administrative court in order to define the priority of "the discrepancies with landscape's peculiarities" or "the overriding public interest" deriving from low-impact energy production.

Such contrast helps introducing the other approach, which could be defined energocratic. This technicalscientific perspective is antithetic and complementary

\footnotetext{
${ }^{2}$ In this respect see the photovoltaic integration on Paul VI Audience (or Nervi) Hall's roofing, in the Vatican City. The project, coordinated by Professor Livio de Santoli from the Sapienza University of Rome and completed in 2008, replaced the tiles facing south with solar panels. The intervention was carried out with particular regard to the aspects concerning perception and visual impact: in fact, it is invisible from the street and only partially visible from the cupola. A careful analysis of Nervi Hall's roofing from the cupola allowed to locate the invisible areas and thus indicate the sections where to install the panels.

3 In the guidelines for the assessment of wind turbines' environmental impact (Linee Guida per la Valutazione dell'Impatto Ambientale degli Impianti Eolici, February 2004) by Toscana's regional administration, for example, the colour of wind towers presents a highly discussed topic among other planning alternatives and mitigation interventions, by being basically in contrast with the context: that is, because of its strong influence on the plant's visibility and in the way it integrates into landscape. The project Mensano is even more significant, featured by Magma Energy Italia in order to build several geothermal plants "disguised" as a Tuscan farmhouse in Val d'Elsa (Ferrara 2013).
} 
to the first and recognizes the ultimate priority of the energy emergency, so great that could legitimate any kind of intervention on the land-especially on those areas lacking a socially accepted cultural value. Nevertheless, when exasperated it leads to a short-sighted and unidirectional view of both projects and intervention policies, thus dividing the humanistic and poetic approach from that technological change whose ineluctable prevalence is so praised. The so called "incentive landscape is the product of recent policies for the incentivization and promotion-particularly on a local level-of tout court energy infrastructures, which have operated in full autonomy without considering the effects on the land.

Even if technology's soteriological power towards the environmental issue may be attributed to Buckminster Fuller's thought (Ingersoll 2009), the resulting project outcomes more often concern energy systems' majority, especially during the first experimentations. These systems are both active and passive; they almost present themselves as "good" vehicles of beauty on the architectural scale, unlike other control factors which concretely and provocatively detach themselves from the context. The symbolic value in terms of communication is even used as a marketing tool, not just in some icon buildings expressing specific business or government choices, ${ }^{4}$ but also at a territorial level to create for example new forms of tourism which treasure energy saving as a value, a tradition or simply an attraction, an economic engine. However, such exploitation sometimes conceals green washing practices which cannot effectively reduce the environmental impact ${ }^{5}$

Still, one fact in particular emerges from the analysis of both approaches: energy systems' integration has generally occurred in juxtaposition with the prevalence of the existent over the new (static-conservative approach) or vice versa (energocratic approach), but without developing a real synthesis which could be translated in a specific language. Even though sustainability's aesthetic potential looks still partially unexplored, both from a compositive and conceptual point of view (Heymann 2012), some rare attempts at changing have been recorded.

A sort of refounding desire shows through some projects, in which new technologies suggest new solutions of various nature: architectural-as far as the choice of

\footnotetext{
${ }^{4}$ Representative examples are the Solar Ark by Sanyo Electric Co. in Anpachi, Japan (2002), the Bahrain World Trade Center by Atkins studio (2008) and the Masdar City project (designed by Foster and Partners in 2006), financed by the Abu Dhabi government (UAE) as a symbolic centre of renewable energies and sustainable buildings.

${ }^{5}$ A controversial example, both from the perspective of the project management and the concept itself, is the newly founded green city Dongtan near Shanghai. The project by Arup studio should have been concluded for Expo 2010, but was never carried out.
}

materials, techniques and typologies is concerned-spatial, ${ }^{6}$ settling and social. For instance, newly constructed eco-districts lay the foundation for a different housing concept, ${ }^{7}$ focusing on the evolution of the urban grid and the relation between buildings and open spaces, as well as on the idea of community. Transformation interventions and technical solutions thus become opportunities to promote the generation process of new regulation and housing practices based on the principle of cooperation between users, on making them aware of their responsibilities, on a shared use of resources and on energy communities' virtuous behaviour.

Another line of research concerns the "reintroduction" of devices, materials and models developed over time by local tradition and adapted to the climatic context, dialoguing with landscape in accordance with ancient matrixes and searching for new interpretations of technological, material and environmental culture in a balanced synthesis between tradition and innovation. Such revivals of local housing traditions, meaning also the revision of building solutions from the pre-industrial and pre-modern phase, combine with strong impulses to innovation in order to introduce hybrid settling backgrounds where the building legacy from the past and the most advanced contemporary solutions even out.

These latter specific perspectives muster the needs of "in-the-round" sustainable development, including both active and passive solutions in a potential integration. Nevertheless, a further approach is emerging, pivoting on the very same core of the appropriate language and focusing on energy infrastructure itself (plant system, including vectors) in relation to landscape. It means exploring forms to eventually solve the contrast between new and existent: a research where projects become creators of beauty aimed at enhancing the energy object's aesthetic, and thus at mitigating or camouflaging its aspect. The desire to lend an architectural image to energy artefacts has significant historical references and presents an interesting evolution (Ciorra 2013), until at last the

\footnotetext{
${ }^{6}$ Some pioneering projects are Ken Yeang's studies on the bioclimatic skyscraper since the 1980s; Dieter Schempp's integration of habitable greenhouses into buildings with different functional destination and LOG ID study in the 1990s; and the proposal of integration between nature and artifice at various level launched by MVRDV with the Dutch pavilion during Expo 2000 in Hannover

7 The first Ecocities display a functionalist, technicist approach and "suffer from an absolute settling seriality, the constant absence of public and aggregation spaces, the implicit inability to build "tissues», the lack of hierarchies and thus of those "orientation and identification factors which are essential to the city's development»" (Maretto 2011). However, from the Bo01 experience in Malmö to Hammarby Sjöstad in Stoccolma and HafenCity in Hamburg has emerged a greater awareness in sustainable planning on a urban scale, able to reformulate mediation between technological, cultural and social aspects and reform urban discipline for 21 st-century cities.
} 
aesthetic of the machine prevailed and relegated these elements to the language of mere infrastructural and productive functionality; such a research has concerned both larger buildings and small service facilities distributed in the territory. This comeback to a stylistic treatment of plant systems manifests itself in restyling operations of the artefact, in plant coachwork (a sort of chassis) and finally through hybridization models ${ }^{8}$ representing the most innovative and promising line among all these project explorations. To the first category we could attribute some new interpretations in terms of industrial design, such as wind turbines ${ }^{9}$ and electricity pylons. ${ }^{10}$ However, the remaking process of the external container (with particular regard to power stations and larger plants) has a recent forerunner: Friedensreich Hundertwasser's lifting of Spittelau refuse incinerator in Wien (built in 1987), besides several other examples in Italy and abroad based on different solution in terms of volumetric composition and use of materials. The hybridization method aims at returning energy artefacts to the city and transforming them into inhabited objects, with different usage possibilities other than simple productive functionality. A sort of reconciliation and humanization, which not only filter through the overcoming of anodyne envelopes, but also introduce both the perceptive and the real fruition of new spaces and more or less public functions. The difference between infrastructures integrated with energy production systems and "inhabited" energy infrastructures diminishes, expanding considerably the experimentation and implementation field of the integration concept.

A similar process can be recognized on a larger planning scale of public space, whether urban or not, where the plant system is integrated with other services and equipment-from furniture to sport-but still retains a specific formal value. Infrastructures thus become the object of artistic manufacturing in land $\operatorname{art}^{11}$ or landscape design ${ }^{12}$ works.

\footnotetext{
8 "The image of energy artefacts is changing and they will continue to lose their traditional industrial look. On the one hand, there is an evolution in the container, which adopts a more amiable or more modern image that is integrated in the environment, and, on the other, the tendency towards hybridization of energy artefacts and other structures, mainly buildings, will lead to hitherto unseen landscapes" (Ivancic 2010).

${ }^{9}$ Like the "Power Flower" vertical-axis wind turbine by NL Architects (2010).

${ }^{10}$ See the "Germoglio" pylons designed by Hugh Dutton Associés for Terna.

11 The Solar Strand in Buffalo, USA (2012) by Hood Design is an interesting example. It transforms the photovoltaic field generated inside the Buffalo University campus in a giant land art installation, which can be enjoyed like an open-air park and visited to promote education and the development of awareness towards renewable energies.

12 Battle i Roig Arquitectes' redevelopment project of Vall d'en Joan landfill (Park of Garraf, Barcelona) is a landscape restoration work which allowed the area to be redesigned and readjusted into landscape, in addition to the extraction of waste-produced biogas.
}

Projects where form prevails over function are the key elements for acceptability and social consensus towards the alteration of the existent. They possess an artistic aura barely suitable for reproduction, and don't risk becoming a mark of specific identification. They represent potential references, but partially encourage technological innovation of materials and components which need a higher demand for mass-production instead.

On the contrary, in this respect the component design could be implemented on broad, scarcely explored land.

\section{The landscapes of energy innovation}

These approaches and lines of research help determining a slow cultural change closely interrelated with technological innovation, which on the contrary manifests itself basically within the specific field of materials and techniques aimed at energy production.

A possible exception might be organic photovoltaic $(\mathrm{OPV})::^{13}$ even though here the high application flexibility exceeds the static and algid appearance of the polycrystalline cell and meets planning integration needs, developing such a solution would be a step towards a reduction of production costs, which undoubtedly pose an important economic restriction for the spreading of renewable energies (Arunachalam and Fleischer 2008).

As opposed to the past, renewable energies' economic success-in terms of investments and spreading, too (International Energy Agency 2015a)-has broken loose from the oscillation of fossil fuel costs by now, because of both technology evolution and market/policies reasons (Nyquist 2015). It means we can no longer speak of "alternative energies", also because technological-scientific innovation has likewise opened new horizons for gas and oil extraction industry, relegating the emergency of their depletion to a historical phase (Yergin 2014). On one hand, renewable energies' progress is relentless, even in those emerging countries where they had been considered uneconomical. However, on the other hand, the definitive supersession of fossil fuels would be an epochal change taking decades. We're talking about slow and difficult incremental innovations, and it's hard to believe in the confidence in substantial innovation as a panacea for near future, given the time constraints and the size of required investments.

Such technological change includes the entire phenomenology of renewable energies, and firstly the large production plants mimicking the fossil energies' landscape colonization characteristics. Indeed, in some cases these plants concentrate in even more distant areas than

\footnotetext{
${ }^{13}$ The first major architectural project experimenting with the integration of organic photovoltaic technology was the German pavilion at Expo 2015 in Milan.
} 
traditional thermoelectric plants, ${ }^{14}$ as compared with the inhabitants' daily perception-obviously save for the problem of transmission networks and relative required infrastructures. In this context, ${ }^{15}$ given the control over investment costs e the relative scarcity of areas easily accessible and not subject to restrictions (mountain areas, coasts, desert areas), the trend proceeds towards the increase of existing plants' efficiency through a scale-up which could possibly represent a risk factor for both the environment and the inhabitants (Schöbel and Dittrich 2010). On the contrary, in other cases such as the biomass case we can also speak of isolated plants, even larger ones, which have pervasive effects on the agricultural landscape as a system, in terms of both a change in cultivations and the correlated social and economic model.

These plants have been arranged on the basis of climate potentials, ${ }^{16}$ according to a very different logic if compared to the past; although this could disrupt the existing geopolitical balance, ${ }^{17}$ the scope of widespread production as an innovative way of using renewable energies is just as revolutionary (Merchant 2015). Here innovation's bottom-up process not only has a purely endogenous nature within the industrial sector, but change also revolves around a mutual interrelation between technological, cultural, physical, social and economic reasons where the cause-effect relationship loses its meaning. This production model is widely patronized by govern policies at international level. Its great success, also with regard to economic perspectives (Klose et al. 2010), is due to the supersession of the univocal concept of user: consumers now become producers, too (prosumers, from the crasis between producer and consumer) and thus theoretically undermine national electricity monopolies. This is made possible by the implementation of smart grids measuring the flows of incomes and expenditures, allowing economic calculation and making users more aware of their own environmental impact, so that they can potentially modify their "non-eco" behaviours and finally free themselves from role subordination.

\footnotetext{
${ }^{14}$ Suffice it to think about the development perspectives of offshore plants (wind and tides) or solar energy which concentrate in the desert areas of the planet.

${ }^{15}$ Renewable energies based on solar radiation as a direct or indirect source and on tides.

${ }^{16}$ Just think of Desertec Project, developed since 2009 by the Trans-Mediterranean Renewable Energy Cooperation (TREC) - a voluntary organization founded in 2003 by the Club of Rome and National Energy Research Center Jordan for renewable energy production from sites where sources are, due to their own nature, more available (e.g. the sunniest deserts of the world).

${ }^{17}$ In this new particular respect we can still speak of alternative energies as opposed to the large fossil energy monopolies.
}

Such innovation 2.0 may be assimilated to the most sector-renowned Information Technology (which perhaps has become a contemporaneity matrix in many fields) and is bound to heavily influence land transformations. At the same time, in the citizen's active, responsible and no longer merely judge-like passive condition lies the key for a cultural shift in landscape as it is perceived and represented. The development perspectives of this innovation focus both on the enhancement of control software and networks and especially, in terms of cost and time efficiency, on the implementation of storage batteries in order to overcome the Achilles heel of these widespread renewable energies: that is, the occasional availability caused by climate and time conditions. At the moment the effects on well-established settling models are conceived as utopia, ranging from distribution networks' future uselessness (perhaps for the benefit of landscape) to the questioning of urban culture for the benefit of a sprawl without hierarchies, where the sum of (selfsufficient) individuals will represent an alternative to the idea of civilized society as mutual coexistence (Hill 2015).

The development and improvement of microgeneration especially in the built environment certainly requires a paradigm shift in the relationship between served buildings and servant infrastructures, also blurring the boundaries between private and public spaces as well as ownership in urban contexts. Accordingly, a new role and approach for design is entailed, in addition to the maturing of a specific new language to integrate the innovative plants in the existing buildings. The increase of building services equipment and infrastructures, as a result of a widespread production, becomes a new layer to be added to the urban landscape, occupying public as well as private areas, especially in dense settlements. Therefore, also the design of public and open spaces will face a general rethinking in order to encompass the new energy infrastructures not as anodyne and alien service objects to be necessarily introduced in existing areas, but as multifunctional devices, to be integrated in order to enhance the usability, the liveability as well as the beauty of urban public spaces, once more, putting into practice the hybridisation approach.

\section{Energy innovation context}

Regardless of possible idealistic projections, widespread energy production is one of the main motives behind landscape's physical transformation. However, it may also prove a tool able to modify its perception, making use of shared ways of the transformation process. More positions within landscape research field address the understanding of its representation's development conditions, and those narratives and cultural stratifications which are chosen to formulate a judgement. A new specific 
discipline called environmental aesthetic identifies one of the keys of positive aesthetic judgement-thus linked to a kind of assessment which is functionalist rather than ethic ${ }^{18}$-in a both multisensory and rational involvement lying in the comprehension of transformation reasons. In this regard, the participation to transformation-both direct and in terms of democratization of the decisionmaking process, as well as of socialization of the reasons behind choices and objectives-could help the inhabitants of a landscape to love it (Selman 2010) and to create consensus. Surely this approach is valid also in the case of top-down decision-making processes, with regard to the building of large plants and the definition of energy policies in general.

To this end and with particular regard to the development of widespread production, from a standpoint of new constructions but especially of energy redevelopment of the existent, Italy at least needs a substantial legislative reform in terms of simplification but also rethinking of the involved subjects' roles and abilities; the potential prosumers also need to be considered, who are mainly private ${ }^{19}$ or result from innovative forms of public-private partnership at a local level. This would entail also the supersession of the rigidities in today's energy market, still fundamentally oligopolistic. Such innovations in the economic and regulatory reference scenario would provide an essential boost to the current tax relief scheme.

In this context the project's aid becomes essential, not just because it could potentially stimulate aesthetic, mitigation or simple technological innovation (all attempts at interpreting change compared with a well-established and yet already existing culture) but also because of the intermediation, direction and systematization role of various social and disciplinary requirements (Ginelli and Daglio 2015).

The design contribution, in fact, through a multidisciplinary and integrated collaboration of diverse

\footnotetext{
${ }^{18}$ In Carlson's opinion the ecological approach to landscape understanding, unlike positions deriving from artistic aesthetic, focuses on ecological rather than cultural factors and interprets artificial environments as human ecosystems comparable to natural ones. As a consequence, aesthetic fruition can capture their "beauty" in the organic unity, because each element of the system (natural and/or artificial) has its role, its function and a synergic and integrated relation with the whole. Such functional fit ensures that landscapes created by human transformation possess an aesthetic, in which culture and nature share the same necessity, appearing as they are and not as mere results of fruition or artistic construction (Carlson 2009, Nature and Landscape: an Introduction to Environmental Aesthetics, Columbia University Press, New York).

19 Condominium institution is particularly opposed, despite its significant spreading within the national context due to both the conservatism deriving from property fragmentation and the impossibility to become a prosumer (unless relying on a third party dealing with intermediation in the energy market).
}

competences should be introduced at the strategic level of the process development, with the purpose of deepening the analysis of the different economic, environmental, social and institutional features of the specific landscape in relationship with the possible new renewable energy plants intervention. An integration in terms of multifunctionality (Ginelli and Daglio 2014) and hybridisation should be explored and evaluated with the aid of participatory processes engaging the different stakeholders to let them mature a deeper knowledge and awareness of the landscape they inhabit in order to be involved actively in the decision making task. The project activity, thus, includes the challenge of supporting inhabitants in the process of comprehension and representation of the landscape transformation, to be part of it and thus to appreciate it (Ginelli and Daglio 2016).

A new landscape representation paradigm emerges, also through the localization of a meeting and synthesis point between landscapes-along with their intrinsic character and local specificity resulting from geographical and historical conditions-and energy as industrial product, whose characteristics tend to homogenization, seriality and indifference towards the place (Nadai and Van Der Horst 2010). Maybe we should just change perspective, interpret the appearance of architecture and landscape and try to spot materiality as a temporary expression of energy (Moe 2013). Such design has to imbue not only strictly disciplinary contexts, ${ }^{20}$ but also the creation of governance policies and models based on qualitative and inclusive soul.

\section{Authors' contributions}

LD contributed for the taxonomy of the interpretative models, and the drafting of the second part of the article. EG critically revised the contents adding significant contribution to the methodological approach of the research. Both authors read and approved the final manuscript.

\section{Acknowledgements}

Not applicable.

Competing interests

The authors declare that they have no competing interests.

Availability of data and materials

All data generated or analysed during this study are included in this published article.

Funding

Not applicable.

\footnotetext{
${ }^{20}$ Many advoke, for example, a major role to landscape design (De Waal and Stremke 2015) with regard to those synergies sometimes generated by the overlapping between renewable energy installations and existing structures (Schöbel and Dittrich 2010). To have a more articulated presentation in terms of the problematic posed by the project's role in the field of energy landscape building see also Angelucci (2011), edited by, La costruzione del paesaggio energetico, Franco Angeli, Milan.
} 


\section{Publisher's Note}

Springer Nature remains neutral with regard to jurisdictional claims in published maps and institutional affiliations.

Received: 28 July 2018 Accepted: 10 October 2018

Published online: 17 October 2018

\section{References}

Angelucci F (ed) (2011) La costruzione del paesaggio energetico. Franco Angeli, Milano

Arunachalam VS, Fleischer EL (2008) The global energy landscape and materials innovation. MRS Bull 33:264-276

Carlson A (2009) Nature and landscape: an introduction to environmental aesthetics. Columbia University Press, New York

Ciorra P (ed) (2013) Energy: architettura e reti del petrolio e del post-petrolio. Electa, Milano

De Waal R, Stremke S (2015) Energy transition: missed opportunities and emerging challenges for landscape planning and designing. Sustainability 6:4386-4415

Ferrara G (2013) Renewable energy sources: side effects. In: Calcagno Maniglio A, Palazzo AL (coordinators) Presentation of the seminar on renewable energies and landscapes, vol 04. I Quaderni di Careggi

Ginelli E, Daglio L (2014) Relationship between energy systems and landscape. Guidelines and tools for design and management. TECHNE 8:137-144 (ISSN: 2239-0243)

Ginelli E, Daglio L (2015) A multidimensional analysis to manage the relation between energy and landscape. In: the fifteenth international conference on civil, structural and environmental engineering computing, Praque 1-4 September 2015. CIVIL-COMP PRESS. http://civil-comp.com/conf/ conf2015/cc2015.htm. Accessed 1 Sept 2015

Ginelli E, Daglio L (2016) Infrastructures for renewable energies in landscape. Design tools and innovation trends. TECHNE 11:119-126 (ISSN: 2239-0243)

Heymann D (2012) An un-flushable urinal. The aesthetic potential of sustainability. Places Journal. PLACESJOURNAL. https://placesjournal.org. Accessed 7 Sept 2015

Hill D (2015) Elon Musk's Powerwall could change the carbon footprint of entire societies. In: Dezeen Magazine. DEZEEN. http://www.dezee n.com/2015/05/14/dan-hill-opinion-elon-musk-powerwall-energy-stori ng-battery-could-change-carbon-footprint-entire-societies/. Accessed 14 July 2015
Ingersoll R (2009) Questione ecologica in architettura. Sustainability?, vol 140. Lotus, Milano, pp 36-48

International Energy Agency (2015a) Tracking clean energy progress 2015. IEA Publications, Paris

International Energy Agency (2015b) Key world strategy statistics 2015. Chirat, Paris

Ivancic A (2010) Energyscapes. Land \& Scapes Series. Barcelona, Gustavo Gili

Klose F, Kofluk M, Lehrke S, Rubner H (2010) Toward a distributed-power world. Renewables and smart grids will reshape the energy sector. In: The Boston Consulting Group Inc. BCG. https://www.bcgperspectives.com/ content/articles/energy_environment_sustainability_toward_a_distr ibuted_power_world/. Accessed 3 Sept 2015

Maretto M (2011) Ecocities ed Ecoquartieri: tra morfologia e progetto urbano. In: ECOCITIES, vol 419. L'Industria delle Costruzioni, pp 4-25

Merchant T (2015) Disruptive power: How innovation is reshaping the energy landscape. FORBES INDIA. http://forbesindia.com/blog/economy-policy/ disruptive-power-how-innovation-is-reshaping-the-energy-landscape/. Accessed 6 Jan 2015

Moe K (2013) The formations of energy in architecture: an architectural agenda for energy. In: Braham WW, Willis D (eds) Architecture and energy: performance and style. Routledge, New York

Nadai A, Van Der Horst D (2010) Introduction: lanscapes of energies. Landsc Res 35(2):143-155

Nyquist S (2015) Lower oil prices but more renewables: What's going on? MCKINSEY \& COMPANY. http://www.mckinsey.com/industries/oil-andgas/our-insights/lower-oil-prices-but-more-renewables-whats-going-on. Accessed Jun 2015

Pasqualetti MJ (2012) Reading the changing energy landscape. In: Stremke S, Van den Dobbelsteen A (eds) Sustainable energy landscape: designing planning and development. CRC Press-Taylor \& Francis Group, Boca Raton

Schöbel S, Dittrich A (2010) Renewable energies_landscapes of reconciliation? Topos 70:54-59

Selman P (2010) Learning to love the landscapes of carbon neutrality. Landsc Res 35(2):157-171

Stremke S (2014) Energy-landscape nexus: Advancing a conceptual framework for the design of sustainable energy landscapes. In: Sörensen C, Liedtke K (eds) Proceedings ECLAS conference 2013. Jovis Verlag, Berlin, pp 392-397

Yergin D (2014) Daniel Yergin on the next energy revolution. MCKINSEY \& COMPANY. http://www.mckinsey.com/business-functions/sustainabilityand-resource-productivity/our-insights/daniel-yergin-on-the-next-energ y-revolution. Accessed Apr 2014

\section{Submit your manuscript to a SpringerOpen ${ }^{\circ}$ journal and benefit from:}

- Convenient online submission

- Rigorous peer review

- Open access: articles freely available online

- High visibility within the field

- Retaining the copyright to your article

Submit your next manuscript at springeropen.com 